\title{
Prevalence of Frailty Syndrome in the Elderly and Associated Factors in Brazil
}

\author{
Anna Ferla Monteiro Silva Passos' ${ }^{1}$, Iris do Céu Clara Costa루 Fábia Barbosa de Andrade ${ }^{3}$, \\ Maria do Carmo Eulálio4, Anita Liberalesso Neri' ${ }^{5}$, Rômulo Lustosa Pimenteira de Melo4, \\ Adrianna Ribeiro Lacerda ${ }^{1}$ \\ ${ }^{1}$ Postgraduation Program in Health Sciences, Federal University of Rio Grande do Norte, Natal, Brazil \\ ${ }^{2}$ Department of Dentistry, Federal University of Rio Grande do Norte, Natal, Brazil \\ ${ }^{3}$ Nursing, Faculty of Health Sciencies of Trairi/Federal University of Rio Grande do Norte, Santa Cruz, Brazil \\ ${ }^{4}$ Department of Psychology, State University of Paraíba, Campina Grande, Brazil \\ ${ }^{5}$ Department of Educational Psychology, State University of Campinas, Campinas, Brazil \\ Email: annaferla@ig.com.br, iris_odontoufrn@yahoo.com.br, fabiabarbosabr@yahoo.com.br, \\ carmitaeulalio@terra.com.br, anitalbn@uol.com.br, romulo.psiq@gmail.com, adriribeiro.cg@bol.com.br
}

Received 27 March 2015; accepted 22 November 2015; published 25 November 2015

Copyright (C) 2015 by authors and Scientific Research Publishing Inc.

This work is licensed under the Creative Commons Attribution International License (CC BY).

http://creativecommons.org/licenses/by/4.0/

(c) (i) Open Access

\begin{abstract}
This paper aims to identify the prevalence of frailty syndrome and its association with demographic, economic, health, psychological and functional variables in Brazilian population. The study was cross-sectional and composed of 385 elderly aged from 65 years, an average age of 73.92 years. A multivariate Poisson regression was used to check for conditions associated with frailty and to determine the prevalence $(\alpha=0.05)$. The prevalence of frailty was $8.7 \%$ and pre-frailty of $50.4 \%$. The frail and pre-frail older adults showed larger and increasing prevalence ratios for marital status, difficulty performing instrumental activities of daily living, old age, involuntary loss of feces, depression and negative affections. These results can guide the establishment of preventive measures and the development of intervention strategies aimed at minimizing the adverse effects of frailty in elderly people.
\end{abstract}

\section{Keywords}

Aging, Frail Elderly, Frailty, Frailty Syndrome

\section{Introduction}

Numerous demographic and epidemiological studies have demonstrated the increasing elderly population

How to cite this paper: Passos, A.F.M.S., Costa, I.C.C., Andrade, F.B., Eulálio, M.C., Neri, A.L., Melo, R.L.P. and Lacerda, A.R. (2015) Prevalence of Frailty Syndrome in the Elderly and Associated Factors in Brazil. Health, 7, 1591-1599. 
worldwide, putting government and society on its own medical and socioeconomic challenges of population aging [1]. According to the World Health Organization (WHO) in 2025, Brazil will be the sixth country in number of elderly in the world, reaching about 32 million seniors. As a consequence, this will increase the impact on the social and economic sphere of the country, which promotes the interest of the scientific community, especially for those considered more fragile and vulnerable [2].

According to the national literature, the prevalence of frailty varies from $5 \%$ to $58 \%$, and this increases proportionally with age [3]. Accordingly, a substantial portion of the elderly population is a carrier of health conditions that make them vulnerable to a large number of adverse events. These individuals are about to pass the barrier of cognitive and functional preservation, developing various frameworks of dependence, being classified as carriers of frailty syndrome-clinical syndrome identified by unintentional weight loss, decreased level of physical activity, reduced palm grip strength, sensation of fatigue and reduced gait velocity. Those characterized as fragile, suffering from three of these symptoms such as pre-frail of one or two non-frail those without symptoms [4].

Although there is no consensus on the definition of frailty in the elderly, there are common markers that indicate that this concept is broad and dynamic. It is characterized by both biomedical and psychosocial factors and is associated with age, decreased lean body mass, muscle strength and endurance, flexibility, balance, coordination, mobility, level of physical activity and cognitive function, increasing the risk for falls, functional decline, worsening of chronic and acute illness, hospitalization, absent or slow recovery from a clinical stage and death [3]-[6].

With the increasing elderly population, studies in health intensified, in particular those related to frailty, so that the identification of the instruments used to characterize the fragile state and enable the indication of relevant clinical markers [6] [7]. The prevalence of the elderly population's frailty has been stated in some studies through a descriptive analysis. In this study the multivariate analysis model was highlighted, in addition to increasing the association of frailty with psychological variables (negatives affections) and health variables (fecal incontinence). The early identification of characteristics associated with frailty syndrome can trigger measures to improve the quality of life of older people and prevent adverse events. Thus, the aim of this study was to identify the prevalence of Frailty Syndrome and its association with demographic, economic, health, psychological and functional variables in Brazilian population.

\section{Methods}

A cross-sectional study in 2009, conducted by Network FIBRA, acronym for "Frailty in Elderly Brazilians". The sample was randomly selected by cluster sampling, with the sampling unit of the urban census sectors a northeastern Brazilian city randomly selected. Subjects were recruited at their homes.

\subsection{Sampling}

We estimated the sample size needed to have a proportion of $50 \%$ of occurrence of a certain characteristic of the elderly population (value at which the sample size is the maximum possible for $p=0.50$ and $q=0.50$ ). The formula used was: $n=\left\{z^{2} \times\left[p \times q /(d)^{2}\right]\right\}$ [8]. The calculation indicated a population of 385 elderly.

\subsection{Data Collection Procedures}

Data collection was performed at the agreed place during recruitment, lasting 40 - 80 minutes. Later, they were asked to sign a Statement of Form Informed Consent (SFIC). The project was approved by the Ethics Committee of the College of Medical Sciences, State University of Campinas No. 208/2007.

Through a structured questionnaire, demographics, self-reported health problems, variables functionality and psychological distress were collected. The Mini Mental State Examination (MMSE) [9], in order to identify seniors who presented cognitive deficits, which could adversely affect the reliability of answers - to the psychological measures of the cognitive screening test was used.

The criteria for inclusion and exclusion were the same used in the Cardiovascular Health Study and Women's Health and Aging Study [10] and based on studies by Fried et al. [11].

\subsection{Techniques and Tools to Measure the Variables}

To associate with the frailty phenotype four groups of variables were considered. The first demographic charac- 
teristics, with the following variables: sex, age, literacy, currently works. The second was composed of selfreported health problems, and asked if they have had a medical condition diagnosed as having hypertension and/or diabetes mellitus or if it happens to have involuntary loss of urine or feces frequently.

The third group of variables worked with tools from the Basic Activities of Daily Living (BADL) [12], Instrumental Activities of Daily Living (IADL) [13] and Advanced Activities of Daily Living (AADL) [14]. Finally, a last group of variables of psychological malaise composed by the Geriatric [15] Depression Scale and a measure of affections [16]. These instruments are described below.

The performance was evaluated using the BADL to the Independence in Activities of Daily Living developed by Sidney Katz [12], which consists of a list of six items organized hierarchically, which asked the seniors if they were totally independent, if they needed help or if they needed help to complete activities related to survival. For IADL, Instrumental Activities of Daily Living created by Lawton and Brody was used to scale on the maintenance of independent living in the household and neighborhood contexts, containing seven activities where the elderly were evaluated according to their performance and/or participation [13]. Already in assessing AADL, an inventory made based on the literature on Advanced Activities of Daily Living, which contained 12 self-report questions on the participation of older people in social roles and social life was more widely used [14].

The Geriatric Depression Scale (GDS) is recommended by the World Health Organization instrument that makes a survey of depressive disorder. His reduced form [15] consists of 15 items that verified the mood and the feeling of the subject in the last two weeks. Scores above 5 points suggests likely depression [16].

The scale of positive and negative affects consists of 14 adjectives, with response options ranging from 1 (nothing) to 5 (extremely). Six of the adjectives related to positive affects (eg. Happy, satisfied, fun, optimistic) and eight related to negative affective states (eg. Depressed, frustrated, angry). Thus, for example, the more the elderly person has experienced the negative affections in recent weeks, the higher their score. The sum of scores in positive affect could range between 5 and 30 and the sum of negative scores could range between 5 and 40 [17].

\subsection{Techniques to Measure the Phenotype of Frailty}

According to the Cardiovascular Health Study and the Women's Health and Aging Study [10], there are five elements of the operational or phenotype definition of frailty syndrome: 1) unintentional weight loss self-report: $\geq 4.5 \mathrm{~kg}$ or $5 \%$ of the body weight in the previous year; 2 ) assessed by self-report the fatigue evoked by two questions of a scale for depression screening, being considered the manifestation of fatigue assertion that in three or more days of the week, the elder felt it needed to make a lot of effort to account for the tasks; 3) low grip strength measured with a portable hydraulic dynamometer in the dominant hand, adjusted for sex and Body Mass Index (BMI); 4) low energy expenditure measured in metabolic equivalent (MET) and adjusted for gender, assessed from self-report physical exercise and housework performed in the last seven days, based on items from the Minnesota Leisure Time Activity Questionnaire validated for Brazil by Lustosa and adapted for this study; 5) Low gait speed indicated by the average time spent to complete three times the distance of $4.6 \mathrm{~m}$, with adjustments for sex and height. For the last three criteria, frailty score for individuals that got results located between $20 \%$ of the sample [11] [18]-[22]. All self-reported measures were considered reliable, since the MMSE was used.

\subsection{Data Analysis}

The data were tabulated in Microsoft Excel software, being exported to the R language, version 2.15.1 and R Commander package, epicalc, Imtest and Sandwich. Initially, we tested the factor structure of the Geriatric Depression measures and Affections, with the use of measures adjustment ( $\chi^{2} / g l$; GFI; AGFI; CFI, RMSEA) and the internal consistency of the factors, verified by Cronbach's Alpha $(\alpha)$.

Subsequently, a bi-variant chi-square test $\left(\chi^{2}\right)$ was performed and a one way ANOVA with post hoc Tukey's test. The tests showed that less than or equal to $5 \%$ probability $(\mathrm{p} \leq 0.05)$ not to exclude the null hypothesis, were taken into account in a multivariate model, which was developed by two Poisson regressions, one where the dependent variable was not frail/pre-frail and another non frail/frail. For keeping variables in the multivariate model, we adopted the stepwise method. A robust estimator was used in the covariance matrix for more robust standards errors. The magnitude of the effects of the regressions was interpreted as a Prevalence Ratio (PR) with 
confidence intervals of 95\%. Those who remained were in the multivariate model variables with less than or equal to $0.05(\alpha=0.05)$ significance.

\section{Results}

Most of the sample is composed of females (70.12\%) with an average age of 73.92 years. Regarding marital status, $46.58 \%$ of them were married and $38.23 \%$ widowed. In addition, $61.77 \%$ are literate and most (85.32\%) reported they were employed.

\subsection{Adjustment Measures of Affections and Geriatric Depression}

Table 1 shows that the scale of affections exposes plausible fit $\left(\chi^{2} / \mathrm{gl}=2.00\right.$, GFI $=0.92$, AGFI $=0.89$, CFI $=$ 0.94 and RMSEA $=0.064$ ), corroborating the two-dimensional structure. The two factors (Positive and Negative Affections) had both alphas of $\alpha=0.85$. Similarly, the depression scale showed acceptable fit, even with the CFI Below that recommended by literature. The other parameters were within the recommended $\left(\chi^{2} / \mathrm{gl}=1.49\right.$, GFI $=$ 0.93 , AGFI $=0.91$, CFI $=0.81$ and RMSEA $=0.046$ ). The alpha of the scale was of $\alpha=0.68$.

\subsection{Description and Prevalence Ratios of the Frailty Phenotype}

The sample exposed prevalence of pre-frail elderly of 50.4\% [95\% CI (45.63 - 55.36)] and the frail elderly of 8.7\% [95\% CI (6.33 - 11.87)]. Table 2 presents the association between frailty profiles (non frail, pre-frail and frail) with the demographic profile. Of the five variables, only gender showed no significant association ( $\mathrm{p}>$ 0.05 ) with the pre-frailty and frailty, even with women representing $71.4 \%$ of frail people. It adds to the pre-frail elderly, with significant gender being 0.07 , approaching that which is accepted in this work and the majority of the literature in this area, still a consensus does not exist, it was decided by not including it in the multivariate models. The other variables, with the exception of marital status that provided no significance for the group of the pre-frail, showed significance for both groups of frailty (Table 2).

Table 1. Parameters of adjustment of the measurement of the affection and geriatric depression scales.

\begin{tabular}{llllllr}
\hline & Model & $\chi^{2}(\mathbf{g l})$ & GFI & AGFI & CFI & RMSEA (IC 90\%) \\
\hline Scale of Affections & Bifactorial & $150.68(75)$ & 0.92 & 0.89 & 0.94 & $0.064(0.049-0.078)$ \\
Geriatric Depression Scale & Unifactorial & $131.21(88)$ & 0.93 & 0.91 & 0.81 & $0.046(0.028-0.062)$ \\
\hline
\end{tabular}

Notes: $\mathrm{N}=785 . \chi^{2}=$ chi-square, $\mathrm{gl}=$ degrees of liberty, GFI = Goodness-of-Fit Index, AGFI = Adjusted Goodness-of-Fit Index, CFI = Comparative Fit Index, RMSEA = Root-Mean-Square Error of Approximation, IC90\% = Interal of Trust $90 \%$.

Table 2. Association of the phenotype of frailty with demographic variables.

\begin{tabular}{|c|c|c|c|c|c|c|c|c|c|}
\hline \multirow{2}{*}{\multicolumn{2}{|c|}{ VARIABLES }} & \multicolumn{2}{|c|}{ NON FRAIL } & \multicolumn{2}{|c|}{ PRE-FRAIL } & \multirow[b]{2}{*}{$\mathbf{p}$} & \multicolumn{3}{|c|}{ FRAIL } \\
\hline & & $\mathbf{F}$ & $\%$ & $\mathbf{F}$ & $\%$ & & $\mathbf{F}$ & $\%$ & $\mathbf{p}$ \\
\hline \multicolumn{10}{|c|}{ Demographics and economics } \\
\hline \multirow{2}{*}{ Sex } & Male & 55 & 35.0 & 53 & 26.1 & \multirow{2}{*}{0.07} & 10 & 28.6 & \multirow{2}{*}{0.46} \\
\hline & Female & 102 & 65.0 & 150 & 73.9 & & 25 & 71.4 & \\
\hline \multirow{4}{*}{ Age groups } & $65-69$ & 63 & 40.1 & 48 & 23.6 & \multirow{4}{*}{$<0.001$} & 9 & 25.7 & \multirow{4}{*}{0.03} \\
\hline & $70-74$ & 50 & 31.8 & 64 & 31.5 & & 8 & 22.9 & \\
\hline & $75-79$ & 24 & 15.3 & 40 & 19.7 & & 7 & 20.0 & \\
\hline & $\geq 80$ & 20 & 12.7 & 51 & 25.1 & & 11 & 31.4 & \\
\hline \multirow{4}{*}{ Marital Status } & Maried of lives with companion & 85 & 54.1 & 87 & 42.9 & \multirow{4}{*}{0.15} & 12 & 34.3 & \multirow{4}{*}{0.03} \\
\hline & Single & 10 & 6.4 & 19 & 9.4 & & 3 & 8.6 & \\
\hline & Divorced, separated & 12 & 7.6 & 14 & 6.9 & & 2 & 5.7 & \\
\hline & Widow & 50 & 31.8 & 83 & 40.9 & & 18 & 51.4 & \\
\hline \multirow{2}{*}{ Literate } & Yes & 111 & 70.7 & 118 & 58.1 & \multirow{2}{*}{0.01} & 15 & 42.9 & \multirow{2}{*}{0.002} \\
\hline & No & 46 & 29.4 & 85 & 41.9 & & 20 & 57.1 & \\
\hline \multirow{2}{*}{ Currently Working } & Yes & 31 & 19.7 & 25 & 12.3 & \multirow{2}{*}{0.05} & 2 & 5.7 & \multirow{2}{*}{0.05} \\
\hline & No & 126 & 80.3 & 178 & 87.7 & & 33 & 94.3 & \\
\hline
\end{tabular}


Table 3 shows the association between the variables of health, functionality and psychological malaise. Those that were statistically significant were the involuntary loss of urine, involuntary loss of stool (specifically for the pre-frail phenotype), difficulties in IADL, depression, and positive and negative affections.

The variables that showed significance in the bi-variant tests were considered for the multivariate model. For the model with the outcome of non frail/pre-frail, with three variables remained significant (Table 4). The age

Table 3. Association of the phenotype of frailty with health, functional and psychological variables.

\begin{tabular}{|c|c|c|c|c|c|c|c|c|c|}
\hline \multirow{2}{*}{ VARIABLES } & & \multicolumn{2}{|c|}{ NON FRAIL } & \multicolumn{3}{|c|}{ PRE-FRAIL } & \multicolumn{3}{|c|}{ FRAIL } \\
\hline & & $\mathbf{F}$ & $\%$ & $\mathbf{F}$ & $\%$ & $\mathbf{p}$ & $\mathbf{F}$ & $\%$ & $\mathbf{p}$ \\
\hline \multicolumn{10}{|l|}{ Health Issues } \\
\hline \multirow{2}{*}{ Hipertension } & Yes & 96 & 61.1 & 134 & 66.0 & \multirow{2}{*}{0.11} & 20 & 57.1 & \multirow{2}{*}{0.76} \\
\hline & No & 60 & 38.2 & 65 & 32.0 & & 15 & 42.9 & \\
\hline \multirow{2}{*}{ Diabetes Mellitus } & Yes & 17 & 10.8 & 22 & 10.8 & \multirow{2}{*}{0.60} & 7 & 20.0 & \multirow{2}{*}{0.098} \\
\hline & No & 91 & 58.0 & 98 & 48.3 & & 16 & 45.7 & \\
\hline \multirow{2}{*}{ Urinary Incontinence } & Yes & 18 & 11.5 & 41 & 20.2 & \multirow{2}{*}{0.002} & 9 & 25.7 & \multirow{2}{*}{0.015} \\
\hline & No & 91 & 58.0 & 79 & 38.9 & & 14 & 40.0 & \\
\hline \multirow{2}{*}{ Fecal Incontinence } & Yes & 3 & 1.9 & 18 & 8.9 & \multirow{2}{*}{0.001} & 3 & 8.6 & \multirow{2}{*}{0.065} \\
\hline & No & 106 & 67.5 & 102 & 50.2 & & 20 & 57.1 & \\
\hline \multicolumn{10}{|c|}{ Functional Capacity } \\
\hline \multirow{2}{*}{ Dificulties in BADL } & Little & 97 & 61.8 & 101 & 49.8 & \multirow{2}{*}{0.18} & 19 & 54.3 & \multirow{2}{*}{0.48} \\
\hline & Much & 12 & 7.6 & 21 & 10.3 & & 4 & 11.4 & \\
\hline \multirow{2}{*}{ Dificulties in IADL } & Little & 104 & 66.2 & 107 & 52.7 & \multirow{2}{*}{0.038} & 13 & 37.1 & \multirow{2}{*}{$<0.01$} \\
\hline & Much & 5 & 3.2 & 15 & 7.4 & & 10 & 28.6 & \\
\hline \multirow{6}{*}{ AADL } & 0.00 & 17 & 10.8 & 20 & 9.9 & \multirow{6}{*}{0.49} & 3 & 8.6 & \multirow{6}{*}{0.36} \\
\hline & 1.00 & 25 & 15.9 & 24 & 11.8 & & 4 & 11.4 & \\
\hline & 2.00 & 22 & 14.0 & 27 & 13.3 & & 6 & 17.1 & \\
\hline & 3.00 & 15 & 9.6 & 23 & 11.3 & & 1 & 2.9 & \\
\hline & 4.00 & 17 & 10.8 & 10 & 4.9 & & 4 & 11.4 & \\
\hline & $>5$ & 13 & 8.3 & 18 & 8.9 & & 5 & 14.3 & \\
\hline \multicolumn{10}{|c|}{ Psychological Variables } \\
\hline Depression & m (dp) & \multicolumn{2}{|c|}{$2.72(2.02)^{\mathrm{a}}$} & \multicolumn{3}{|c|}{$4.28(2.55)^{\mathrm{b}}$} & \multicolumn{2}{|c|}{$5.39(2.80)^{b}$} & $<0.001$ \\
\hline Positive Affections & m (dp) & 22.2 & $63)^{\mathrm{a}}$ & & $21.16(4$ & & 20. & $.22)^{\mathrm{b}}$ & 0.013 \\
\hline Negative Affections & m (dp) & 15.1 & $11)^{\mathrm{a}}$ & & 17.74 (5 & & & $13)^{b}$ & $<0.001$ \\
\hline
\end{tabular}

BADL: Basic Activities of Daily Living; IADL: Instrumental Activities of Daily Living; AADL: Advanced Activities of Daily Living; a, b, c: different letters, represent significant differences, verified by the post hoc Turkey test $(\mathrm{p}<0.05)$.

Table 4. Multivariate model for the non frail/pre-frail outcomes.

\begin{tabular}{|c|c|c|c|c|c|c|c|}
\hline \multirow{2}{*}{\multicolumn{2}{|c|}{ Pre frAil }} & \multirow{2}{*}{ B } & \multirow{2}{*}{ Std. Error } & \multirow{2}{*}{ Sig. } & \multirow{2}{*}{$\mathbf{R P}$} & \multicolumn{2}{|c|}{$95 \%$ IC } \\
\hline & & & & & & Lower & Upper \\
\hline \multirow{4}{*}{ Age Group } & Between 65 - 69 years & $0^{\mathrm{a}}$ & . & . & & . & . \\
\hline & Between 70 - 74 years & 0.10 & 0.05 & 0.05 & 1.10 & 1.00 & 1.21 \\
\hline & Between 75 - 79 years & 0.15 & 0.05 & 0.01 & 1.16 & 1.037 & 1.30 \\
\hline & Less than 80 years & 0.15 & 0.06 & 0.02 & 1.16 & 1.029 & 1.31 \\
\hline \multirow{2}{*}{ Literate } & Yes & $0^{\mathrm{a}}$ & . & . & & . & . \\
\hline & No & 0.07 & 0.04 & 0.09 & 1.07 & 0.98 & 1.16 \\
\hline \multirow{2}{*}{ Fecal incontinence } & No & $0^{\mathrm{a}}$ & . & . & & . & . \\
\hline & Yes & 0.13 & 0.05 & 0.01 & 1.14 & 1.029 & 1.26 \\
\hline Depression & & 0.03 & 0.01 & 0.01 & 1.03 & 1.017 & 1.05 \\
\hline
\end{tabular}

$0^{\mathrm{a}}$ : Parameter of Reference. 
groups of older exposed higher prevalence of pre-frail group of the elderly between 65 and 69 years. The elderly who reported involuntary loss of feces also were significantly more prevalent, and finally, the data shows that the higher the scores on depression, the more frequent are the pre-frail.

The data relating to the multivariate model for non frail/frail outcome are shown in Table 5. In it, four variables remained statistically significant. The single, married and widowed had a higher prevalence of frailty compared to separate elderly. In addition, older people have more difficulty in IADL and showed a higher prevalence in frailty, as well as higher scores of depression and negative affections.

\section{Discussion}

Frailty Syndrome was found in $59.1 \%$ of the elderly studied. A systematic review [6] observed in the analysis of 18 studies, a wide variation in prevalence of frailty in general from $6.9 \%$ to $21 \%$ for the frail state and $33 \%$ to $55 \%$ for pre-frail state. The prevalence of frailty (8.7\%) and pre-frailty (50.4\%) values were slightly above those observed in a survey of elderly North Americans: pre-frail (7\%) and frail (47\%) [10]. An investigation on 993 Spanish elderly over 70 years showed much higher results for the weakness (16.9\%) [23]. Similar numbers were found in a study involving 601 community-dwelling elderly in the Brazilian city of Belo Horizonte (8.7\%) [24]. This wide variation may be attributed to the use of different models and methodology for identifying weak phenotypes, in addition to existing social and economic realities in different samples.

Among the demographic variables, a higher prevalence of pre-frailty in elderly people with older ages was identified. These data corroborate the national level [24] investigations and international [11] [23]-[25] linking the fragility of old age. Its association with advancing age has no explanation for the characteristic of the aging process, in which physiological changes in neuro-muscular-skeletal function and all body systems suffer losses and occur both in the structural and functional aspects [25]. It was also observed that poor socioeconomic and educational conditions, little formal education and low income characteristics are present in most debilitated people [26].

Association between frailty and marital status was found, since, single, widowed and married elderly had a higher prevalence to be a frail elderly when compared to separate ones. In the scientific literature, studies to a discussion of the relationship between these variables were not found.

The relationship between frailty and comorbidities can be determined by immunological dysfunction, neuro-endocrine deregulation and chronic inflammatory processes, as well as organic structural changes predisposing individuals to diseases such as hypertension, diabetes mellitus, cerebral vascular accident, renal failure, osteoarthritis and depression [4] [11].

Among the conditions associated with a significantly higher prevalence of frailty and pre-frailty have fecal incontinence and depression. Unpublished data found in this study was the association between frailty and involuntary loss of stool in the elderly indicating a significance not reported in the literature on the topic: high prevalence of pre-frailty (1.14 times) among the elderly who have fecal incontinence compared to elderly people who have the same condition. Among morbidities investigated in a cross-sectional descriptive Brazilian survey

Table 5. Multivariate model for the non frail/frail outcomes.

\begin{tabular}{|c|c|c|c|c|c|c|c|}
\hline \multirow{2}{*}{\multicolumn{2}{|c|}{ FRAILTY }} & \multirow{2}{*}{ B } & \multirow{2}{*}{ Std. Error } & \multirow{2}{*}{ Sig } & \multirow{2}{*}{$\mathrm{RP}$} & \multicolumn{2}{|c|}{ IC $95 \%$} \\
\hline & & & & & & Lower & Upper \\
\hline \multirow{4}{*}{ Marital Status } & Separated & $0^{\mathrm{a}}$ & . & . & & . & . \\
\hline & Single & 0.50 & 0.18 & 0.01 & 1.64 & 1.16 & 2.32 \\
\hline & Married & 0.34 & 0.11 & 0.01 & 1.41 & 1.13 & 1.75 \\
\hline & Widow & 0.43 & 0.13 & 0.01 & 1.54 & 1.20 & 1.97 \\
\hline \multirow{2}{*}{ Fecal incontinence } & No & $0^{\mathrm{a}}$ & . & . & & . & . \\
\hline & Yes & 0.27 & 0.18 & 0.10 & 1.31 & 0.93 & 1.84 \\
\hline \multirow{2}{*}{ Difficulty in IADL } & Little & $0^{\mathrm{a}}$ & . & . & & . & . \\
\hline & A lot & 0.45 & 0.13 & 0.01 & 1.57 & 1.22 & 2.03 \\
\hline Depression & & 0.05 & 0.02 & 0.01 & 1.06 & 1.01 & 1.10 \\
\hline Negative Affections & & 0.02 & 0.01 & 0.04 & 1.02 & 1.00 & 1.03 \\
\hline
\end{tabular}

$0^{\mathrm{a}}$ : Parameter of Reference; IADL: Instrumental Activities of Daily Living. 
[27] the following prevalence were found: $13.4 \%$ for depression and $5.6 \%$ for fecal incontinence.

The true incidence of this disorder channel is not accurate, however, it is estimated that may affect up to $5 \%$ of the general population, with higher prevalence in the elderly and women [28]. Chronic morbidities, particularly those associated with pain and/or loss of function, often added in the elderly and are most commonly involved with the occurrence of frailty [29].

More research is needed to examine the prevalence of fecal incontinence with frailty, since few studies have been found in the scientific literature and the pathogenesis of this condition may be present in old age or diseases associated with belonging to the clinical and surgical areas.

Depressive symptoms were strongly associated with frailty syndrome. Elderly people with depression had higher prevalence for frailty and pre-frailty compared with those who did not have depression. The growing trend of depression and weakness is reinforced by several studies [24] [30].

Depression is considered as one of the most frequent agents of emotional distress and significant decrease in the quality of life in old age. The occurrence of psychiatric symptoms increases with age and both levels of satisfaction with the levels of positive and negative emotions are influenced by biological, social and intra-psychic vulnerability inherent in the elderly [26].

In this sense, considering a possible psychosocial or psychological component as a predisposing factor of fragility, there seems to be a relationship between negative affections and the prevalence of the same. This study reveals an innovative way that elderly people that have a higher score in negative affections are more prevalent to be a frail elderly. Although negative affect components and frailty in the elderly has not been disclosed previously, it is remarkable that their respective theoretical concepts are different but interrelated.

The findings of this study corroborate international studies [5] [11] and national [24] the extent that they also found a significant association between difficulty in performing IADL with frailty. In a study in the United States, the results suggested that, the beginning of the frailty syndrome, it affects the more complex routine activities and less so the simplest routine activities [11]. In it the authors found 59.7\% of frail elderly with difficulty to perform IADL.

In the current research, those with difficulty performing IADL showed a higher prevalence of frailty. The relationship between disability and frailty is evident primarily in IADL and a loss in these contributes to the reduction of advanced activities of daily living related to the social environment, cultural, religious, political and labor with tendency to isolation, corroborating research conducted in different populations [5] [24].

In the studied population, the prevalence of frailty in numbers is similar to other studies found. Among elderly surveyed, we identified factors associated with frailty syndrome, as that in the presence of it have higher chances for adverse health conditions.

\section{Conclusions}

Understanding relationships with certain variables that showed significance was limited. In this sense, it is suggested to conduct further research to allow other interpretations. Importantly, the investigation will continue, this is the first study of a longitudinal research on indicators of frailty. The multivariate model used shows that it is necessary to consider not only biological, but also psychological factors for understanding Frailty Syndrome.

The results show that the apprehension of signs and symptoms that are predictors of frailty in elderly aids in the development of strategies and interventions aimed at minimizing the adverse effects to the health of the elderly, which represents an essential step in the quest for improved quality of life.

\section{Acknowledgements}

The manuscript received financial support from the National Research Council—CNPq, the Coordination Development of Higher Education Personnel-CDHEP, the Foundation for Research Support of the State of São Paulo-FRSSSP and the Foundation for Research Support of the State of Rio Grande do Sul_FRSSRGS. All authors contributed to the completion of the study and participated in the analysis, interpretation of data, drafting and critical revision and agreed on the final version.

\section{Disclosure}

I declare that neither I nor the other authors or any first degree relative, possess financial and personal interests in the subject matter discussed in the manuscript. No potential conflicts of interest were disclosed. 


\section{References}

[1] Veras, R. (2009) Envelhecimento populacional contemporâneo: Demandas, desafios e inovações. Revista de Saúde Pública, 43, 548-554. http://dx.doi.org/10.1590/S0034-89102009000300020

[2] Ota, A., Yasuda, N., Horikawa, S., Fujimura, T. and Ohara, H. (2007) Differential Effects of Power Rehabilitation on Physical Performance and Higher-Level Functional Capacity among Community-Dwelling Older Adults with a Slight Degree of Frailty. Journal of Epidemiology, 17, 61-67. http://dx.doi.org/10.2188/jea.17.61

[3] Sternberg, S.A., Wershof, S.A., Karunananthan, S., Bergman, H. and Mark, C.A. (2011) The Identification of Frailty: A Systematic Literature Review. Journal of the American Geriatrics Society, 59, 2129-2138. http://dx.doi.org/10.1111/j.1532-5415.2011.03597.x

[4] Oliveira, D.R., Bettinelli, L.A., Pasqualotti, A., Corso, D., Brock, F. and Erdmann, A.L. (2013) Prevalence of Frailty Syndrome in Old People in a Hospital Institution. Revista Latino Americana de Enfermagem, 21, 891-898. http://dx.doi.org/10.1590/S0104-11692013000400009

[5] Fried, P.L., Ferrucci, L., Darer, J., Williamson, J.D. and Anderson, G. (2004) Untangling the Concepts of Disability, Frailty, and Comorbidity: Implications for Improved Targeting and Care. Journal of Gerontology: Medical Sciences, 59, 255-263. http://dx.doi.org/10.1093/gerona/59.3.m255

[6] Tribess, S. and Oliveira, R.J. (2011) Biological Fragility Syndrome in the Elderly: Systematic Review. Revista de Salud Pública, 13, 853-864. http://dx.doi.org/10.1590/S0124-00642011000500014

[7] Remor, C.B., Bós, A.J.G. and Werlang, M.C. (2011) Características relacionadas ao perfil de fragilidade no idoso. Scientia Medica, 21, 107-112.

[8] Silva, N.N. (2001) Amostragem probabilística: Um curso introdutório. 2nd Edition, EdUSP, São Paulo.

[9] Brucki, S.M.D., Nitrini, R., Caramelli, P., Bertolucci, P.H.F. and Okamoto, I.H. (2003) Sugestões para o uso do miniexame do estado mental no Brasil. Arquivos de Neuropsiquiatria, 61, 777-778. http://dx.doi.org/10.1590/S0004-282X2003000500014

[10] Ferrucci, L., Guralnik, J.M., Studenski, S., Fried, L.P., Cutler Jr., G.B. and Walston, J.D. (2004) Designing Randomized, Controlled Trials Aimed at Preventing or Delaying Functional Decline and Disability in Frail, Older Persons: A Consensus Report. Journal of the American Geriatrics Society, 52, 625-624. http://dx.doi.org/10.1111/j.1532-5415.2004.52174.x

[11] Fried, L.P., Tangen, C.M., Walston, J., Newman, A.B., Hirsch, C., Gottdiener, J., et al. (2001) Frailty in Older Adults: Evidence for a Phenotype. Journal of Gerontology: Medical Sciences, 56, 146-157. http://dx.doi.org/10.1093/gerona/56.3.m146

[12] Katz, S., Ford, A.B., Moskowitz, R.W., Jackson, B.A. and Jaffe, M.W. (1963) Studies of Illness in the Aged. The Index of ADL: A Standardized Measure of Biological and Psychosocial Function. The Journal of the American Medical Association, 185, 914-919. http://dx.doi.org/10.1001/jama.1963.03060120024016

[13] Lawton, M.P. and Brody, E.M. (1969) Assessment of Older People: Self-Maintaining and Instrumental Activities of Daily Living. Gerontologist, 9, 179-186. http://dx.doi.org/10.1093/geront/9.3 Part 1.179

[14] Reuben, D.B., Laliberte, L., Hiris, J. and Mor, V. (1990) A Hierarquical Exercise Scale to Measure Function at the Advanced Activities of Daily Living (AADL) Level. Journal of the American Geriatrics Society, 38, 855-861. http://dx.doi.org/10.1111/j.1532-5415.1990.tb05699.x

[15] Yesavage, J.A., Brink, T.L., Rose, T.L., Lum, O., Huang, V., Adey, M. and Leirer, V.O. (1983) Development and Validation of a Geriatric Depression Screening Scale: A Preliminary Report. Journal of Psychiatric Research, 17, 37-49. http://dx.doi.org/10.1016/0022-3956(82)90033-4

[16] Almeida, O.P. and Almeida, S.A. (1999) Confiabilidade da versão brasileira da Escala de Depressão em Geriatria (GDS) versão reduzida. Arquivos de Neuropsiquiatria, 57, 421-426. http://dx.doi.org/10.1590/S0004-282X1999000300013

[17] Siqueira, M.M.M., Martins, M.C.F. and Moura, O.I. (1999) Construção e validação fatorial da EAPN: Escala de Ânimo Positivo e Negativo. Revista da Sociedade de Psicologia do Triângulo Mineiro, 2, 34-40.

[18] Fried, L.P. and Walston, J.M. (2003) Frailty and Failure to Thrive. In: Hazzard, W.R., Blass, J.P., Ettinger Jr., W.H., Halter, J.B. and Ouslander, J., Eds., Principles of Geriatric Medicine and Gerontology, 5th Edition, MacGraw-Hill, New York, 1487-1502.

[19] Batistoni, S.S.T., Neri, A.L. and Cupertino, A.P.F.B. (2010) Validade e confiabilidade da versão Brasileira da Center for Epidemiological Scale-Depression (CES-D) em idosos Brasileiros. Psico-USF, 15, 13-22. http://dx.doi.org/10.1590/S1413-82712010000100003

[20] Rauen, M.S., Moreira, E.A.M., Calvo, M.C.M. and Lobo, A.S. (2008) Avaliação do estado nutricional de idosos institucionalizados. Revista de Nutrição, 21, 303-310. http://dx.doi.org/10.1590/S1415-52732008000300005 
[21] Ainsworth, B.E., Haskell, W.L., Whitt, M.C., Irwin, M.L., Swartz, A.M., Strath, S.J., et al. (2000) Compendium of Physical Activities: An Update of Activity Codes and MET Intensities. Medicine and Sciences in Sports and Exercise, 32, S498-S516. http://dx.doi.org/10.1097/00005768-200009001-00009

[22] Guralnik, J.M., Simonsick, E.M., Ferrucci, L., Glynn, R.J., Berkman, L.F. and Blazer, D.G. (1994) A Short Physical Performance Battery Assessing Lower Extremity Function: Association with Self-Reported Disability and Prediction of Mortality and Nursing Home Admission. Journal of Gerontology: Medical Sciences, 49, 85-94. http://dx.doi.org/10.1093/geronj/49.2.M85

[23] Abizanda, P., Romero, L., Sánchez-Jurado, P.M., Martínez-Reig, M., Gómez-Arnedo, L. and Alfonso, S.A. (2013) Frailty and Mortality, Disability and Mobility Loss in a Spanish Cohort of Older Adults: The FRADEA Study. Maturitas, 74, 54-60. http://dx.doi.org/10.1016/j.maturitas.2012.09.018

[24] Vieira, R.A., Guerra, R.O., Giacomin, K.C., de Souza Vasconcelos, K.S., de Souza Andrade, A.C., Pereira, L.S.M., et al. (2013) Prevalência de fragilidade e fatores associados em idosos comunitários de Belo Horizonte, Minas Gerais, Brasil: dados do estudo FIBRA. Cadernos de Saúde Pública, 29, 1631-1643. http://dx.doi.org/10.1590/S0102-311X2013001200015

[25] Lenardt, M.H., Carneiro, N.H.K., Betiolli, S.E., de Melo Neu Ribeiro, D.K. and Wachholz, P.A. (2013) Prevalence of Pre-Frailty for the Component of Gait Speed in Older Adults. Revista Latino Americana de Enfermagem, 21, 734-741. http://dx.doi.org/10.1590/S0104-11692013000300012

[26] Neri, A.L. (Orgs.) (2013) Fragilidade e Qualidade de Vida na Velhice. Editora Alínea, Campinas.

[27] Faria, C.A., Lourenço, R.A., Ribeiro, P.C.C. and Lopes, C.S. (2013) Desempenho cognitivo e fragilidade em idosos clientes de operadora de saúde. Revista de Saúde Pública, 47, 923-930. http://dx.doi.org/10.1590/S0034-8910.2013047004451

[28] Fruehauf, H. and Fox, M.R. (2012) Anal Manometry in the Investigation of Fecal Incontinence: Totum pro parte, not pars pro toto. Digestion, 86, 75-77. http://dx.doi.org/10.1159/000339633

[29] Lang, P.O., Michel, J.P. and Zekry, D. (2009) Frailty Syndrome: A Transitional State in a Dynamic Process. Gerontology, 55, 539-549. http://dx.doi.org/10.1159/000211949

[30] Guerrero-Escobedo, P., Tamez-Rivera, O., Amieva, H. and Avila-Funes, J.A. (2014) Frailty Is Associated with Low Self-Esteem in Elderly Adults. Journal of the American Geriatrics Society, 62, 396-398. http://dx.doi.org/10.1111/jgs.12679 